\title{
Thermodynamic, Microscopic and Surface Properties of Zn-In Liquid Alloy at $700 \mathrm{~K}$
}

\author{
H. K. Limbu ${ }^{1}$, K. K. Mishra ${ }^{1}$, J. Nirala ${ }^{1}$, I.S. Jha ${ }^{1}$, B.P. Singh ${ }^{2}$, D. Adhikari ${ }^{1}$ \\ ${ }^{1}$ Department of Physics, Mahendra Morang Aadarsh Multiple Campus, Tribhuvan University, Biratnagar \\ Nepal. \\ ${ }^{2}$ University Department of Physics, T.M. Bhagalpur University, Bhagalpur, India
}

\begin{abstract}
The alloying behaviour of Zn-In liquid alloys at 700K has been studied by using Flory's model which is a statistical mechanical model. In this model we assume the role of interchange energy ( $\omega)$ and size factor $\phi$, $\Phi=\vartheta_{B} / \vartheta_{A}$, where $\vartheta_{B}>\vartheta_{A}, \vartheta_{i}(i=A, B)$ represent the atomic volume of the constituent species of the atomic volume of the alloys. The thermodynamic properties and microscopic properties have been computed. Surface property is studied with the help of Butler's model while viscosity is computed from Kaptay equation, and the Moelwyn-Hughes equation. Both the viscosity and surface tension of the alloy increase with increase in concentration of Zn, and computed viscosity show small negative deviation. In this work, the value of interchange energy $(\omega)$ is found to be positive which suggests that there is a tendency of like atoms pairing (Zn$\mathrm{Zn}$ and In-In), as the nearest neighbours indicating the phase separation or segregation in $\mathrm{Zn}$-In liquid alloys. The temperature dependence of interchange energy ( $\omega)$ has been found during the computation of energy of mixing $\left(S_{M}\right)$ and heat of mixing $\left(H_{M}\right)$.
\end{abstract}

Keywords: Thermodynamic properties, Structural properties, Surface properties, Transport properties

\section{Introduction}

To understand the mixing behaviour of two elemental metals forming a binary alloy has always been a subject of considerable interest to physicists, chemists and metallurgists. Usually the merit of formation of an alloy is judged from the observed characteristic thermo-physical functions that deviate from the ideal mixing condition. The Zn-In system is not only a system of great importance from metallurgical point of view, it is also interesting for the study the high temperature lead free soldier [1]. Metal physicists [1]-[26] have keen interest in the concentration dependent asymmetry in the properties of mixing of binary liquid alloys and hence to extract additional microscopic information. In metallurgical science, the study of mixing properties of alloys is important because a good knowledge of their mixing properties in the liquid state is necessary for preparation of desired materials. Viscosity of the liquid state is required for many metallurgical processes and heterogeneous chemical reactions. Surface properties are required to understand the surface related phenomena such as corrosion, wetting characteristics of solders and kinetics of phase transformation [2]. The mixing behaviour of binary liquid have been explained by several theoreticians on the basis of several models [4], [8], [22], [27][39].The size effect (i.e. $\frac{\vartheta_{\mathrm{B}}}{\vartheta_{\mathrm{A}}}=1.68$ where $\vartheta$ stands for atomic volume) is more than $1.5 \mathrm{in} \mathrm{Zn}$-In which is noticeable and it is good to exhibit the observed asymmetry; it is therefore expected that concentration dependent asymmetry arises due to size effects. Therefore, we have used Flory's model[22] to explain anomaly and the mixing behaviour of Zn-In liquid alloy at 700K .In Flory's model[22] the interaction energy parameter is considered as temperature dependent and is determined by fitting experimental free energy of mixing at different concentrations. The mixing behaviour of binary liquid alloys may be explained in terms of thermodynamic and microscopic properties. Thermodynamic behaviour of the alloy is understood by the knowledge of free energy of mixing $\left(\mathrm{G}_{\mathrm{M}}\right)$, activity (a), heat of mixing $\left(\mathrm{H}_{\mathrm{M}}\right)$ and the entropy of mixing $\left(\mathrm{S}_{\mathrm{M}}\right)$. Structural behaviour is interpreted by the chemical short range order parameters $\left(\alpha_{1}\right)$, and the concentration fluctuation in long wavelength limit $\{\operatorname{Scc}(0)\}$. Theory of Flory's model has been presented in section(3), results and discussion is dealt in section-4, and conclusion is provided in section-5.

\section{(A) Thermodynamic and Structural Properties}

\section{Formalism}

The alloying behavior of liquid alloys can be studied with the help of either the electronic theory of mixing [40] or the statistical mechanical theory of mixing. Flory's model [22] is best applicable for the determination of thermodynamic and microscopic properties whenever there is difference in size of the atomic species in a liquid alloy. Flory's expression for the free energy of mixing of a binary mixture A-B consists of $\mathrm{c}_{\mathrm{A}}$ $(\equiv \mathrm{c})$ and $\mathrm{c}_{\mathrm{B}}(\equiv 1-\mathrm{c})$ respectively, where $\mathrm{c}_{\mathrm{A}}$ and $\mathrm{c}_{\mathrm{B}}$ are the mole fractions of $\mathrm{A}(\equiv \mathrm{Zn})$ and $\mathrm{B}(\equiv \mathrm{In})$ in the binary 
liquid alloy A-B. Thus free energy of mixing of those alloys whose constituent atoms differ widely in size can be expressed as

$$
\mathrm{G}_{\mathrm{M}}=\mathrm{RT}[\mathrm{clnc}+(1-\mathrm{c}) \ln (1-\mathrm{c})]+\mathrm{G}(\operatorname{size})+\mathrm{c}(1-\mathrm{c}) \mathrm{G}(\omega)
$$

where $\mathrm{G}$ (size) and $\mathrm{G}(\omega)$ are contributions due to the size effect and the interchange energy respectively which can be written from Flory's model as

$$
\begin{aligned}
& \beta=1-1 / \Phi, \Phi=\vartheta_{\mathrm{B}} / \vartheta_{\mathrm{A}} \\
& \mathrm{G}(\omega)=1 /(1-\beta \mathrm{c}) \\
& \mathrm{G}(\text { size })=\mathrm{RT}[\operatorname{cln}(1-\beta)-\ln (1-\beta c)]
\end{aligned}
$$

where $\vartheta_{A}$ and $\vartheta_{B}$ are atomic volumes of the pure species A and B respectively; $\left(\vartheta_{\operatorname{In}} / \vartheta_{\mathrm{Zn}}=1.68\right)$.

Here, $\quad \vartheta_{\mathrm{T}}=\vartheta_{\mathrm{M}}\left(1+\alpha\left(T-T_{M}\right)\right)$

$\vartheta_{\mathrm{T}}=$ atomic volume at desired temperature

$\vartheta_{\mathrm{M}}=$ atomic volume at melting temperature

$\mathrm{T}_{\mathrm{M}}=$ melting temperature and

$\alpha=$ volume coefficient at constant temperature

From Flory's model the expression for free energy of mixing is given by

$$
\mathrm{G}_{\mathrm{M}}=\mathrm{RT}[\mathrm{c} \ln \mathrm{c}+(1-\mathrm{c}) \ln (1-\mathrm{c})+\mathrm{c} \ln (1-\beta)-\ln (1-\beta \mathrm{c})]+\frac{\omega \mathrm{c}(1-\mathrm{c})}{(1-\beta c)}
$$

The activity $\mathrm{a}_{\mathrm{A}}$ of the element $\mathrm{A}$ in the binary liquid alloy is given as,

$\operatorname{lna}_{\mathrm{A}}=\ln [\mathrm{c}(1-\beta) \eta(\mathrm{c})]+\beta(1-\mathrm{c}) \eta(\mathrm{c})+(1-\mathrm{c})^{2} \eta^{2}(\mathrm{c}) \omega / \mathrm{RT}$

The temperature derivative of $\mathrm{G}_{\mathrm{M}}$ gives an expression for integral entropy of mixing

$S_{M}=-R G(i d)-R G(\operatorname{size})-c(1-c) \eta(c) \cdot \frac{\partial \omega}{\partial T}+R T c(1-c) \eta(c) \times[\beta /(1-\beta)-c \eta(c) \omega / R T] \partial \beta / \partial T$

where,

$$
\begin{aligned}
& \partial \beta / \partial \mathrm{T}=\left(\alpha_{B}-\alpha_{A}\right) v_{A} / v_{B} \\
& \eta(\mathrm{c})=1 /(1-\beta c)
\end{aligned}
$$

Here, $\alpha_{A}$ and $\alpha_{B}$ are the coefficients of thermal expansion of pure species A and B respectively.First term in the right hand side in the equation (8) is due to ideal term and the second term is due to size factor $(\phi)$. The third and fourth term represent the temperature derivative terms of size factor and interchange energy. The necessity of taking $\omega$ as temperature dependent was noticed in[6].

Now, heat of mixing can be obtained from equation (1) and (8) from standard thermodynamic relation,

$$
\begin{aligned}
& \quad \frac{H_{M}}{R T}=\frac{S_{M}}{R}+\frac{G_{M}}{R T} \\
& \frac{H_{M}}{R T}=c \ln c+(1-c) \ln (1-c)+c \ln (1-\beta)-\ln (1-\beta c)+\frac{c(1-c)}{(1-\beta c)} \cdot \frac{\omega}{R T}-\alpha(c)-\Phi(c)-\frac{1}{R} \frac{c(1-c)}{(1-\beta c)} \cdot \frac{\partial \omega}{\partial T}+ \\
& \frac{T c(1-c)}{(1-\beta c)} \cdot\left[\frac{\beta}{(1-\beta)}-\frac{c}{(1-\beta c)} \frac{\omega}{R T}\right] \cdot \frac{\partial \beta}{\partial T} \\
& \text { where, } \\
& \alpha(c)=[c \ln c+(1-c) \ln (1-c)] \text { and } \phi(c)=[c \ln (1-\beta)-\ln (1-\beta c)]
\end{aligned}
$$

To understand the atomic order in binary liquid alloy it is instructive to study the behavior of the long wavelength limit of the concentration-concentration structure factor $[\operatorname{Scc}(0)]$ gives as

$$
\mathrm{S}_{\mathrm{cc}}(0)=\frac{\mathrm{RT}}{\left(\frac{\partial^{2} \mathrm{G}_{\mathrm{M}}}{\partial \mathrm{c}^{2}}\right) \mathrm{T}, \mathrm{P}, \mathrm{N}}
$$

Equation (1) and (13) gives the expression for concentration fluctuation in the long wavelength limit i.e.

$$
\mathrm{S}_{\mathrm{cc}}(0)=\frac{\mathrm{c}_{\mathrm{A}} \mathrm{c}_{\mathrm{B}}}{\left[1-\frac{\mathrm{c}_{\mathrm{A}} \mathrm{C}_{\mathrm{B}}}{(1-\beta c)^{3}}\left\{2(1-\beta) \frac{\omega}{\mathrm{RT}}-\beta^{2}(1-\beta c)\right\}\right]}
$$

The experimental determination of $\operatorname{Scc}(0)$ poses more difficulty but can be determined from measured activity data and is treated as experimental values given as

$$
\mathrm{S}_{\mathrm{cc}}(0)=(1-c) a_{A}\left(\frac{\partial a_{A}}{\partial c}\right)_{T, P, N}^{-1}=c a_{B}\left(\frac{\partial a_{B}}{\partial c}\right)_{T, P, N}^{-1}
$$

where $\mathrm{a}_{\mathrm{A}}$ and $\mathrm{a}_{\mathrm{B}}$ are the activities of the component of $\mathrm{A}$ and $\mathrm{B}$ respectively.

The Warren-Cowley short range order parameter $\alpha_{1}$ can be estimated from the knowledge of $\operatorname{Scc}(0)$ as

$$
\alpha_{1}=\frac{s-1}{s(\mathrm{Z}-1)+1}
$$

where, $\mathrm{Z}=$ coordination number. In present calculation we have used $\mathrm{Z}=8,9$ and 10 .

\section{(B) Transport properties}

Viscosity of liquid alloys helps to understand the mixing behavior of binary liquid alloys at microscopic level. It is one of the important transport properties. In order to examine the atomic transport behavior in $\mathrm{Zn}$-In alloy, we have employed Kaptay equation [41] and the Moelwyn-Hughes equation [42] at 700K. Kaptay equation for the viscosity of the binary alloys at temperature $\mathrm{T}$ is given as

$$
\eta=\frac{\mathrm{hN}_{\mathrm{A}}}{\sum_{\mathrm{K}} \mathrm{C}_{\mathrm{K}} \Omega_{\mathrm{K}}+\Omega^{\mathrm{E}}} \exp \left[\frac{\sum_{\mathrm{K}} \mathrm{C}_{\mathrm{K}} \mathrm{G}_{\mathrm{K}}^{*}-\theta \cdot \mathrm{H}_{\mathrm{M}}}{\mathrm{RT}}\right]
$$


where, $\mathrm{h}=$ Plank's constant, $\mathrm{N}_{\mathrm{A}}$ is Avogadro's number, $\mathrm{R}$ is the ideal gas constant, $\Omega_{\mathrm{K}}$ is the molar volume of component $\mathrm{K}(\mathrm{K}=\mathrm{A}, \mathrm{B}) ; \Omega^{\mathrm{E}}$ is the excess molar volume upon alloy formation, $\mathrm{H}_{\mathrm{M}}$ is enthalpy of mixing of the alloy, $\mathrm{C}_{\mathrm{K}}(=\mathrm{A}, \mathrm{B})$ represents concentration, $\mathrm{G}_{\mathrm{K}}^{*}$ the Gibb's energy of activation of the viscous flow in pure component $\mathrm{K}$ and $\Theta$ is a constant whose value is taken to be $0.155 \pm 0.015[16]$. $\mathrm{G}_{\mathrm{K}}^{*}$ of component $\mathrm{K}$ can be calculated from the expression

$$
\mathrm{G}_{\mathrm{K}}^{*}=\mathrm{RT} \ln \left(\frac{\eta_{\mathrm{K}} \Omega_{\mathrm{K}}}{\mathrm{hN}}\right)
$$

where, $\Omega_{\mathrm{K}}$ is the viscosity of pure component $\mathrm{K}$ and for most liquid metals, it can be calculated from Arrhenius type equation [43] at temperature $\mathrm{T}$ as

$$
\eta_{\mathrm{K}}=\eta_{\mathrm{OK}} \exp \left[\frac{E_{\mathrm{n}}}{\mathrm{RT}}\right]
$$

where, $\eta_{\mathrm{OK}}$ is constant (in unit of viscosity) and En is the energy of activation of viscous flow for pure metal (in unit of energy per mole).

The Moelwyn-Hughes equation [42] for viscosity of liquid mixture is given as

\section{(C) Surface properties}

$$
\eta=\left(c_{1} \eta_{1}+c_{2} \eta_{2}\right)\left(1-2 c_{1} c_{2} \cdot \frac{H_{M}}{R T}\right)
$$

The surface tension of the initial melt has great influence on the formation of solid alloys by the solidification process. The surface properties help to understand metallurgical modeling, description and prediction of structure development during solidification in the binary alloys. In our work, the Butler's equation [44] is employed to study its surface tension. Butler's assumed the existence of surface monolayer at the surface of a liquid as a separate phase that is in thermal equilibrium with the bulk phase and derived an expression

$\Gamma=\Gamma_{1}+\frac{1}{\mathrm{~A}_{1}}\left(\mathrm{G}_{1}^{\mathrm{E}, \mathrm{s}}-\mathrm{G}_{1}^{\mathrm{E}, \mathrm{b}}\right)+\frac{\mathrm{RT}}{\mathrm{A}_{1}}\left[\ln \left(1-\mathrm{X}_{2}^{\mathrm{s}}\right)-\ln \left(1-\mathrm{X}_{2}^{\mathrm{b}}\right)\right]=\Gamma_{2}+\frac{1}{\mathrm{~A}_{2}}\left(\mathrm{G}_{2}^{\mathrm{E}, \mathrm{s}}-\mathrm{G}_{2}^{\mathrm{E}, \mathrm{b}}\right)+\frac{\mathrm{RT}}{\mathrm{A}_{2}}\left[\ln \left(\mathrm{X}_{2}^{\mathrm{s}}\right)-\ln \left(\mathrm{X}_{2}^{\mathrm{b}}\right)\right]$

where, $\Gamma_{1}$ and $\Gamma_{2}$ are the surface tension of the pure component 1 and 2 respectively. $G_{i}^{E, s}$ and $G_{i}^{E, b}(i=1,2)$ are partial excess free energies,$X_{i}^{S}$ and $X_{i}^{b}$ are mole fraction of component $i$ in the surface and bulk respectively The molar surface area of the component $\mathrm{i}$ can be computed by using the relation

$$
\mathrm{A}_{\mathrm{i}}=\mathrm{K} \cdot \mathrm{N}_{\mathrm{A}}^{1 / 3} \cdot \mathrm{V}_{\mathrm{i}}^{2 / 3}
$$

where, $\mathrm{K}(=1.091)$ is geometrical factor for the liquid alloy [14]. For binary mixture $\mathrm{X}_{1}^{\mathrm{b}}+\mathrm{X}_{2}^{\mathrm{b}}=\mathrm{X}_{1}^{\mathrm{s}}+\mathrm{X}_{2}^{\mathrm{s}}=1$.

\section{(A) Free energy of mixing}

\section{Results and Discussion}

For the computation of free energy of mixing $\mathrm{G}_{\mathrm{M}} / \mathrm{RT}$ of molten $\mathrm{Zn}$-In alloy as a function of concentration at $700 \mathrm{~K}$ energy parameter and size factor are required. This parameter i.e. interchange energy $\omega$ has been determined from equation (1) conjugation with equation (6) with the help of experimental values of $\mathrm{G}_{\mathrm{M}}[45]$ in the concentration range of $\mathrm{C}_{\mathrm{Zn}}=.01$ to 0.9 by the method of successive approximation and the value of size factor $\phi$ is obtained by equation (3) in the alloying temperature. The best fit parameter $\omega / \mathrm{RT}$ was found to be 1.428 and the value of size factor $(\phi)$ is 1.68 . The interaction energy $\omega$ is positive, showing that $\mathrm{Zn}$ and In atoms are repelled to each other. Both the theoretical and experimental values are negative at entire concentrations. The computed values are compared with experimental values [45] at any concentration. The theoretical value shows minimum at $\mathrm{c}_{\mathrm{Zn}}=0.3$ and the experimental value shows minimum at $\mathrm{C}_{\mathrm{Zn}}=0.4$ as shown in Figure (1). The theoretical minimum value of $\mathrm{G}_{\mathrm{M}}=-0.2955 \mathrm{RT}$ while experimental minimum value $\mathrm{G}_{\mathrm{M}}=-$ $0.2941 \mathrm{RT}$. The computed and experimental values of free energy of mixing are in good agreement in entire concentration range.

\section{(B) Activity}

Activity is computed using equation (7) conjugation with equation (10). Measurement of activities within a class of similar system will provide a basis for correlation of the behavior. $\ln _{\mathrm{A}}$ is plotted in Figure (2) and is computed with the experimental value of activity [45]. Good agreement between the computed and experimental value is observed for both the lower and higher concentration of $\mathrm{Zn}$. Some disagreement between the equi-atomic composition noticed in $\mathrm{C}_{\mathrm{Zn}}>0.6$ as depicted in Figure 2. 


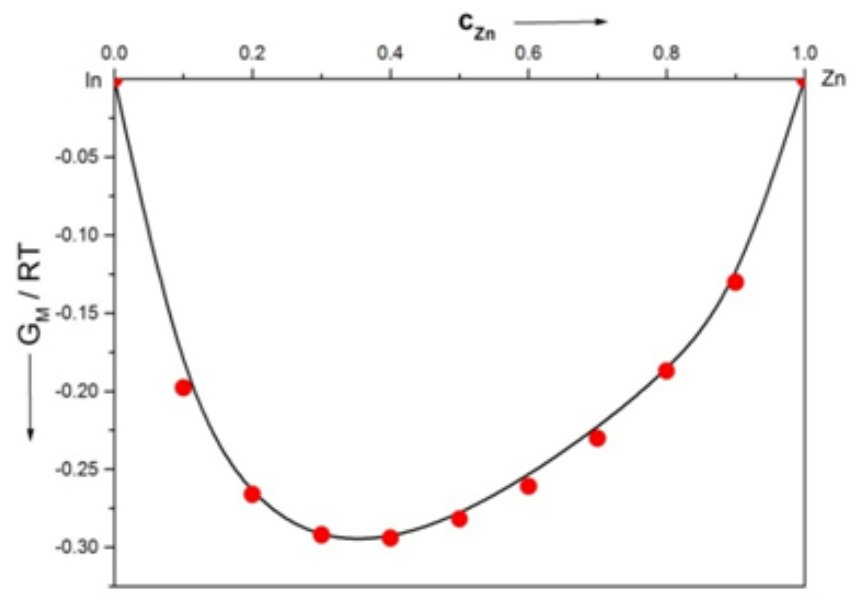

Fig. 1 : Free energy of mixing of Zn-In liquid alloys at $700 \mathrm{~K}$. The solid line represents theoretical values and circle represents experimental values.

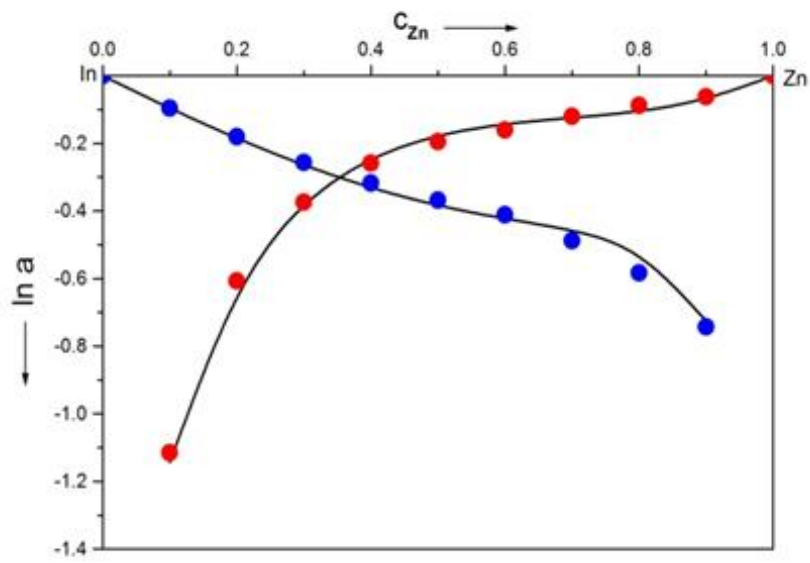

Fig.2: Activities azn and $a_{\text {In }}$ of Zn-In liquid alloys at $700 \mathrm{~K}$. The solid line represents theoretical values and circle represents experimental values.

\section{(C) Entropy of mixing}

To determine the entropy of mixing $\left(\mathrm{S}_{\mathrm{M}}\right)$ using equation (8) we need temperature derivative of energy parameter. The observed value of entropy of mixing [45] was utilized to obtain the temperature derivative by the successive approximation. The best fit parameter was found to be $\frac{1}{\mathrm{R}} \frac{\partial \omega}{\partial \mathrm{T}}=-0.39$. It is found that the term containing $\frac{\partial \beta}{\partial T}$ does not contribute much and for all practical purpose it may be neglected. The effect is only due to the ideal term and the term containing size factor which gives positive deviation and the term containing derivative of interchange energy which deviate negatively which almost cancels each other leaving the effect of ideal term for entropy of mixing. This simply suggests the importance temperature dependent term in entropy of mixing.

The theoretical and experimental values of $\mathrm{S}_{\mathrm{M}} / \mathrm{R}$ against $\mathrm{C}_{\mathrm{Zn}}$ are plotted in Figure 3. The theoretical and experimental values are in well agreement. The theoretical values shows maximum $\left(\mathrm{S}_{\mathrm{M}} / \mathrm{R}=0.8378\right)$ at $\mathrm{C}_{\mathrm{Zn}}=0.5$.

\section{(D) Heat of mixing}

Heat of mixing $\left(\mathrm{H}_{\mathrm{M}}\right)$ has been calculated from equation (12) using the same interaction parameters $\omega / \mathrm{RT}=1.428$ and $\frac{1}{\mathrm{R}} \frac{\partial \omega}{\partial \mathrm{T}}=-0.39$ as used in computing $\mathrm{G}_{\mathrm{M}}$ and $\mathrm{S}_{\mathrm{M}}$. The plot of $\mathrm{H}_{\mathrm{M}} / \mathrm{RT}$ versus $\mathrm{C}_{\mathrm{Zn}}$ at $700 \mathrm{~K}$ is depicted as shown in Figure 4 which shows that like the experimental values [45], $\mathrm{H}_{\mathrm{M}}$ is positive at entire concentrations of $\mathrm{Zn}$. There is a reasonable agreement between theory and experiment. The maximum of $\mathrm{H}_{\mathrm{M}} / \mathrm{RT}$ is observed around $\mathrm{C}_{\mathrm{Zn}}=0.6$, which corresponds to stoichiometric concentration or compound formation composition. It is interesting to observe that concentration dependent asymmetry in $\mathrm{H}_{M}$ as observed from the experiment can be explained if one considers the temperature dependence of energy parameters for $\mathrm{Zn}$-In liquid alloys. 


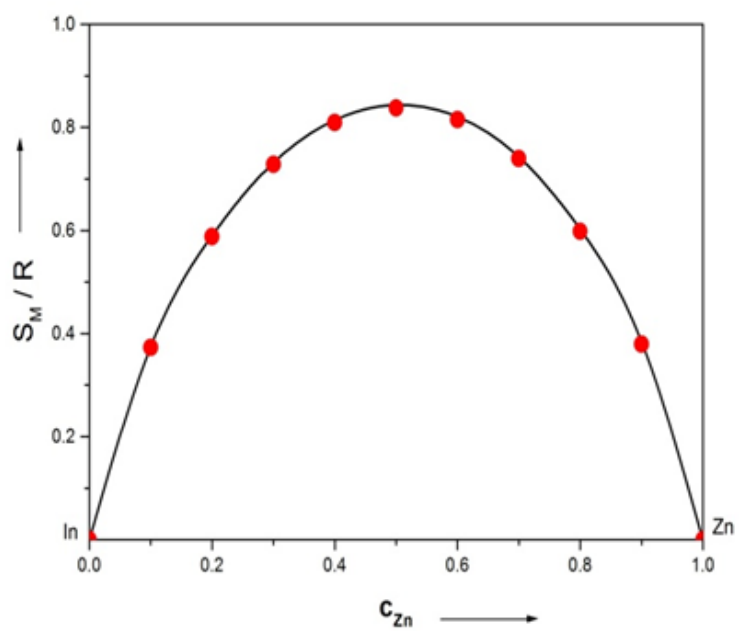

Fig. 3:Entropy of mixing of $\mathrm{Zn}$-In liquid alloys at $700 \mathrm{~K}$. The solid line represents theoretical values and circle represents experimental values.

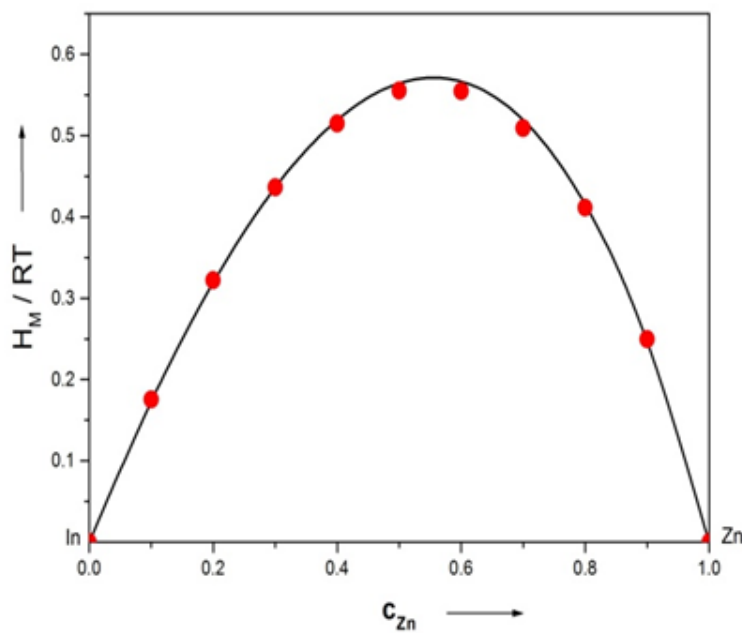

Fig. 4:Heat of mixing of Zn-In liquid alloys at $700 \mathrm{~K}$. The solid line represents theoretical values and circle represents experimental values

\section{(E) Concentration fluctuation}

The concentration fluctuation in long wavelength limit $\operatorname{Scc}(0)$ has emerged as a very useful thermodynamic parameter to investigate the atomic order in a binary liquid alloy. The deviation of $\operatorname{Scc}(0)$ from the ideal values $S_{\mathrm{cc}}^{\mathrm{id}}(0)=\mathrm{c}(1-\mathrm{c})$ can be used to visualize the nature of atomic order and the stability of the mixture at a given composition. If at a given composition $\operatorname{Scc}(0)>\operatorname{Scc}(\mathrm{id})(0)$ there is a tendency of segregation. On the other hand, $\operatorname{Scc}(0)<S_{c c}^{\text {id }}(0)$ refers to hetro-coordination. The theoretical values of $\operatorname{Scc}(0)$ are computed from equation (14) using the same interaction parameter used to calculate $\mathrm{G}_{\mathrm{M}}$. The theoretical and experimental values are depicted in Figure 5. The curve shows maximum at $\mathrm{C}_{\mathrm{Zn}}=0.7(=2.0855)$ while the experimental curves shows maximum at $\mathrm{C}_{\mathrm{Zn}}=0.5(=1.11987)$. Our theoretical investigation shows that $\operatorname{Scc}(0)>\mathrm{S}_{\mathrm{cc}}^{\mathrm{id}}(0)$ in the entire concentration range i.e. $\mathrm{C}_{\mathrm{Zn}}=0.1$ to 0.9 suggesting that $\mathrm{Zn}$-In system is segregating and is quite asymmetric around equi- atomic composition. That is to say that homo-coordination ( preferring for like atoms to be paired as nearest neighbours ) exists in the molten alloy of Zn-In system.

\section{(F) Short range order parameter}

In order to obtain better insight in the nature of arrangement of atoms, we have calculated the WarenCowley short range order parameter $\left(\alpha_{1}\right)$ for Zn-In alloy at 700K. Short range order parameter $\left(\alpha_{1}\right)$ can be evaluated theoretically form the knowledge of $\operatorname{Scc}(0)$ using equation (16). At equi-atomic one has $-1 \leq \alpha_{1} \leq 1$. The minimum value of $\alpha_{1}=-1$ which implies complete ordering and $\alpha_{1}=+1$ corresponds to segregation leading to the phase separation and $\alpha_{1}=0$ implies a random distribution of atoms. We have found that $\alpha_{1}$ is positive at all 
the concentrations of $\mathrm{Zn}$ for $\mathrm{Zn}$-In alloy which is indicative of segregation or phase separation as evident from $\operatorname{Scc}(0)$. In our present work we have computed the value of short range order parameters for different values of coordination numbers (i.e. $\mathrm{Z}=8,9,10$ ) as shown in Figure 6. The values of short range order parameter have been found maximum at $\mathrm{C}_{\mathrm{Zn}}=0.7$ in all three coordination number thus the asymmetry in $\alpha_{1}$ is distinctly visible. The plot of computed values of $\alpha_{1}$ of the alloy is segregating system of like atoms (i.e. $\mathrm{Zn}-\mathrm{Zn}$ and In-In) as nearest neighbours.

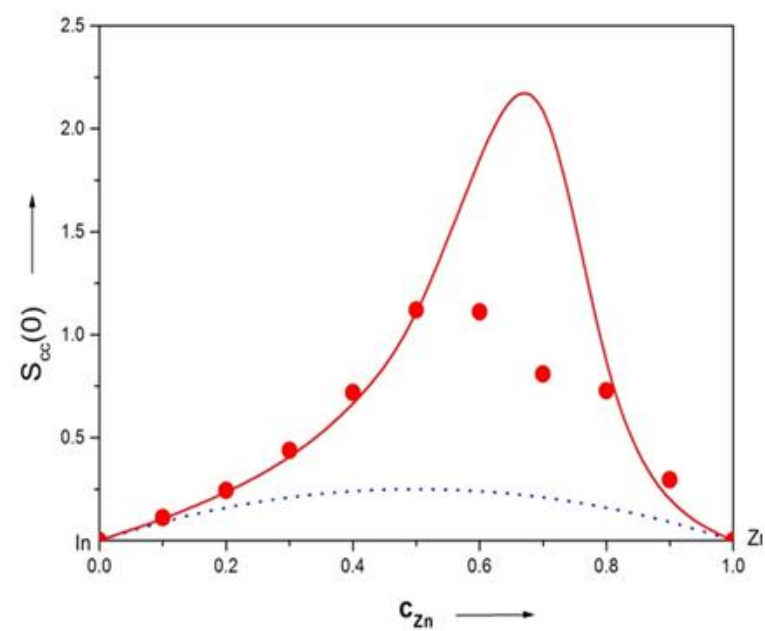

Fig. 5: Concentration fluctuation of $\mathrm{Zn}$-In liquid alloys at $700 \mathrm{~K}$. The solid line represents theoretical values, dotted line represents ideal values and circle represents experimental values.

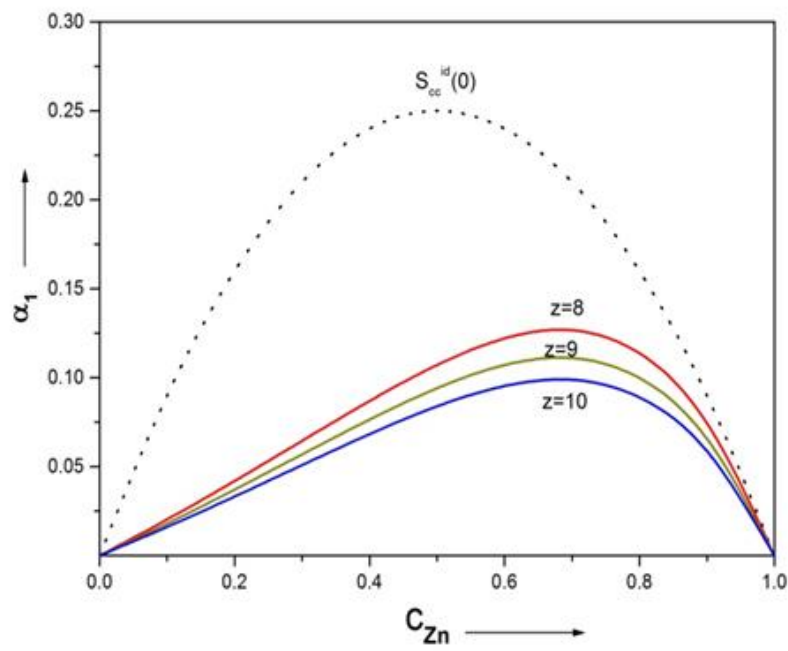

Fig. 6: Chemical short range parameter $\left(\alpha_{1}\right)$ of $\mathrm{Zn}$-In liquid alloys at $700 \mathrm{~K}$ for different co-ordination number $\mathrm{Z}=8,9$ and 10 .

\section{(G) Surface tension}

The surface tension of the liquid alloys can be computed using equation (21) and (22). The ratio of partial excess Gibbs energy in the bulk and that in the surface can be expressed as

$$
\beta=\frac{G_{i}^{E, s}}{G_{i}^{E, b}}
$$

where, $\mathrm{G}_{\mathrm{i}}^{\mathrm{E}, \mathrm{s}}$ and $\mathrm{G}_{\mathrm{i}}^{\mathrm{E}, \mathrm{b}}$ are the partial excess free energy in the surface and that in the bulk. The value of excess mixing of the pure component are taken from Hultgren et al. [45]. The value of parameter $\beta$ has been taken as 0.83 as suggested by different researchers[14] to compute surface tension of liquid alloys. We have taken the surface tension of $\mathrm{Zn}$-In and temperature coefficients for pure $\mathrm{Zn}$ and $\mathrm{In}$ components from the reference [43]. The surface tension of the pure component at temperature of study have been computed by the equation

$$
\Gamma(\mathrm{T})=\Gamma_{\mathrm{m}}+\frac{\partial \Gamma}{\partial \mathrm{T}}\left(\mathrm{T}-\mathrm{T}_{\mathrm{m}}\right)
$$


where, $\frac{\partial \Gamma}{\partial \mathrm{T}}\left(=-0.17 \mathrm{mNm}^{-1} \mathrm{~K}^{-1}\right.$ for $\mathrm{Zn}$, and $-0.09 \mathrm{mNm}^{-1} \mathrm{~K}^{-1}$ for $\left.\mathrm{In}\right)$ and $\left(\mathrm{T}_{\mathrm{M}}=692.5 \mathrm{~K}\right.$ for $\mathrm{Zn}$, and $430 \mathrm{~K}$ for In) are coefficient of surface tension and melting temperature respectively.

The partial excess free energy of mixing of the pure component are taken from Hultgren et al [45]. It is found form the analysis that computed surface tension for $\mathrm{Zn}$-In system at $700 \mathrm{~K}$ is less than ideal value $\left(=\mathrm{C}_{1} \Gamma_{1}+\right.$ $\mathrm{C}_{2} \Gamma_{2}$ ) at all concentration of $\mathrm{Zn}$ i.e. there is negative departure of surface tension from ideality (Figure 7). It is found that surface concentration of $\mathrm{Zn}$ in $\mathrm{Zn}-\mathrm{Sn}$ alloy is found to increase on increasing the bulk concentration of $\mathrm{Zn}$ as shown in Figure 8. This is an indication that in the alloy there are more atoms of component with bigger atoms at the surface. Hence, at the surface of $\mathrm{Zn}$-In, In atoms segregate at the surface in preference of $\mathrm{Zn}$ atoms throughout the entire composition.

\section{(H) Viscosity}

We have used Kaptay equation [34] and Moelwyn-Hughes equation [42] to evaluate viscosity of the alloy and compared the results. To compute viscosity of $\mathrm{Zn}$-In alloy at 700K, the viscosities of pure components $\mathrm{Zn}$ and In at $700 \mathrm{~K}$ are required. To calculate viscosity from Moelwyn -Hughes equation requires heat of mixing $\left(\mathrm{H}_{\mathrm{M}}\right)$. Heat of mixing is calculated from Flory's model calculation. And , to calculate the viscosity with Kaptay equation enthalpy of mixing $\left(\mathrm{H}_{\mathrm{M}}\right)$, the Gibbs free energy of activation of various viscous flow of pure components $\left(\mathrm{G}^{*}\right)$ and excess molar volume of the alloy $\left(\Omega^{\mathrm{E}}\right)$ are required. For simplicity, $\Omega^{\mathrm{E}}$ is taken as zero in our calculation. The viscosities of the alloy calculated from different methods are compared along with ideal values ( Figures 9 and 10). Both Kaptay equation and Moelwyn-Hughes model show small negative deviation from ideal value.

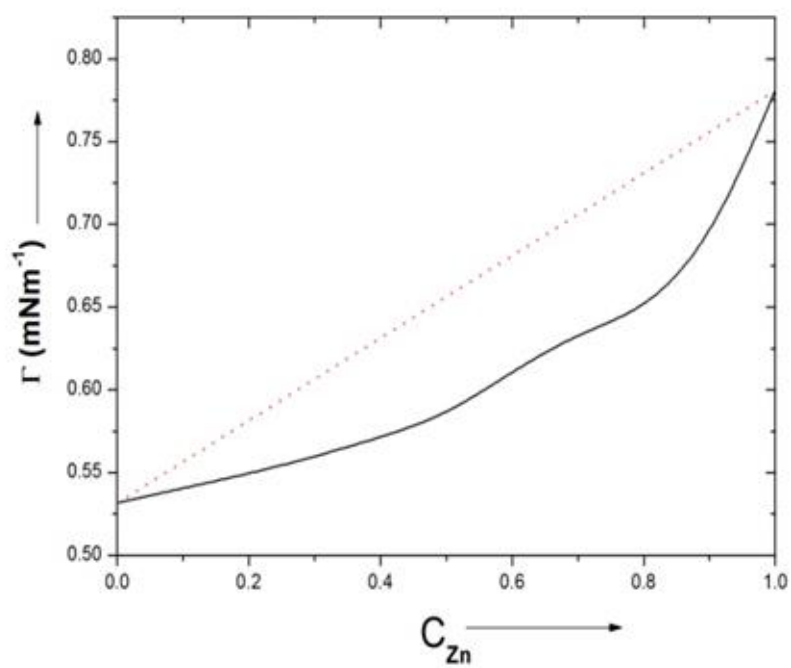

Fig 7: Surface tension of Zn-In liquid alloy at $700 \mathrm{~K}$. Solid line is calculated surface tension and dotted line is ideal surface tension.

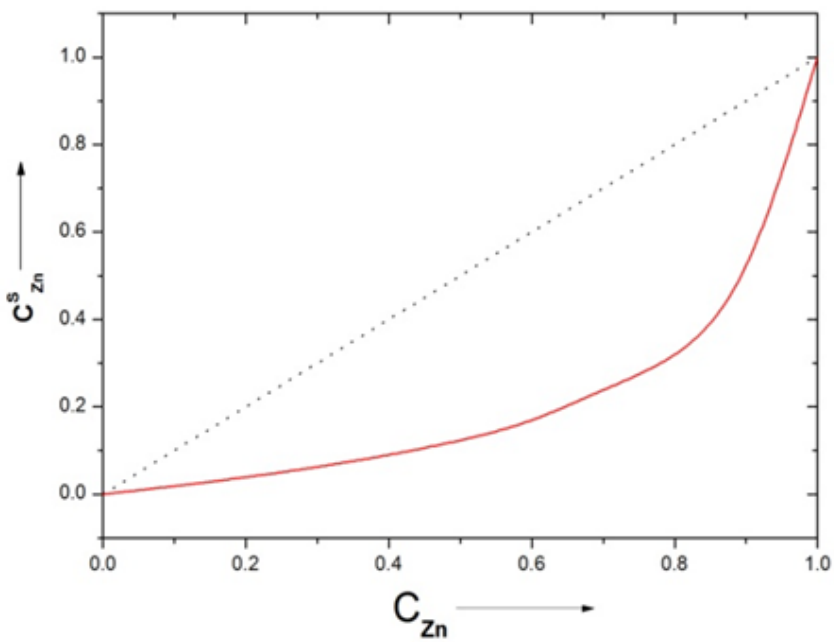

Fig 8 :The surface concentration of $\mathrm{Zn}$ versus bulk concentration of $\mathrm{Zn}$ in molten $\mathrm{Zn}$-In liquid alloy at $700 \mathrm{~K}$. 


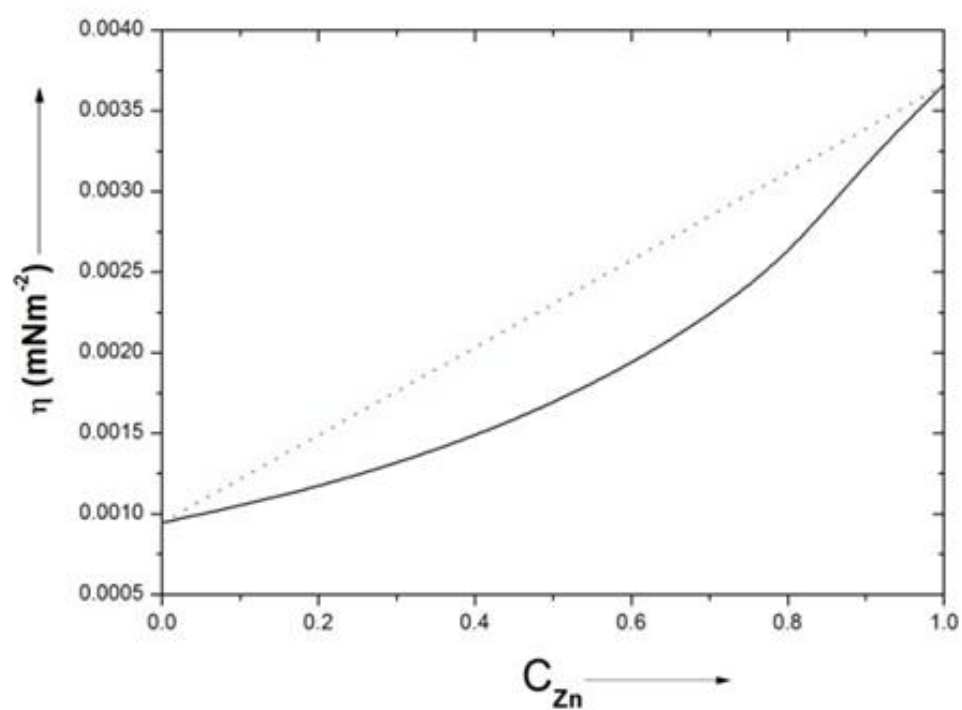

Fig 9 : Viscosity $(\eta)$ of $\mathrm{Zn}$-In liquid alloy at 700K versus concentration of $\mathrm{Zn}$ using Kaptay equation.

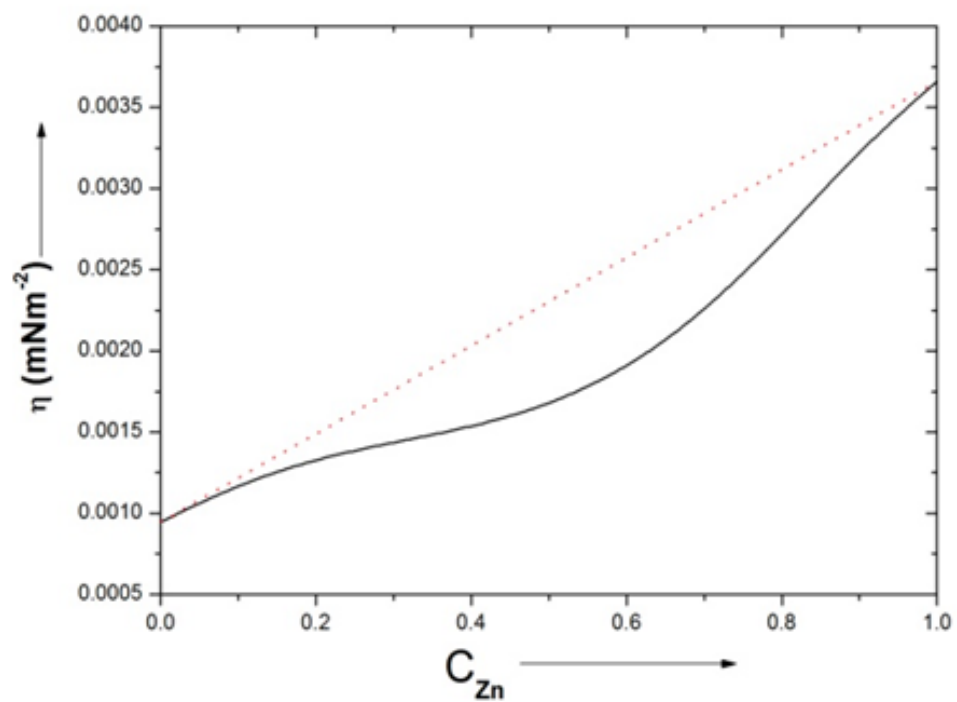

Fig 10 : Viscosity $(\eta)$ of Zn-In liquid alloy at 700K versus concentration of Zn using Kaptay and MoelwynHughes relations.

\section{Conclusion}

The Zn-In alloys in molten state is a weakly interacting system. The ordering energy is temperature dependent. The $\mathrm{Zn}$ - In liquid alloy is segregating in nature. The ordering energy and size factor play an important role to explain the alloying behavior of the liquid Zn-In alloy. Viscosity and surface tension increase with increase in the concentration of $\mathrm{Zn}$.

\section{References}

[1]. J. Lee, K. S. Kim, K. Suganuma, M. Inoue, and G. Izuta, "Thermal properties and phase stability of Zn-Sn and Zn-In alloys as high Temperature lead-free solder," Mater. Trans., vol. 48, pp. 584-593, 2007.

[2]. H. Bake and M. M. Avedesian, Eds., ASM Specialty Handbook:Magnesium and Magnesium Alloys. ASM International, Materials Park, OH, 1999.

[3]. A. B. Bhatia, W. H. Hargrove, and N. H. March, "Concentration fluctuations in conformal solutions and partial structure factor in alloys," J. Phys. C Solid State Phys., vol. 6, no. 4, pp. 621-630, Feb. 1973.

[4]. M. Hoch, "Application of the complex model to liquid metal-salt systems," Calphad, vol. 9, no. 1, pp. 59-70, Jan. 1985.

[5]. S. Harada, S. Takahashi, S. Takeda, S. Tamaki, P. Gray, and N. E. Cusack, "Thermodynamic properties of liquid Na-Cd and NaIn," J. Phys. F Met. Phys., vol. 18, no. 12, pp. 2559-2567, Dec. 1988.

[6]. $\quad$ F. E. Neale and N. E. Cusack, "Thermodynamic properties of liquid sodium-caesium alloys," J. Phys. F Met. Phys., vol. 12, no. 12, pp. 2839-2850, Dec. 1982.

[7]. $\quad$ D. Adhikari, "Disorder in liquid Cu-Pd alloys," Phase Transitions, vol. 84, no. 4, pp. 308-314, 2011.

[8]. G. Kaptay and Z. Papp, "On the concentration dependence of the surface tension of liquid metallic alloys: theoretical basis," $J$. 
Forensic Res., vol. 6, no. 5, 2015.

[9]. M. Shimoji, Liquid Metals. Academic Press, 1977.

[10]. W. H. Young, "Structural and thermodynamic properties of NFE liquid metals and binary alloys," Reports Prog. Phys., vol. 55, no. 10 , pp. 1769-1853, Oct. 1992.

[11]. K. S. Yeum, R. Speiser, and D. R. Poirier, "Estimation of the surface tensions of binary liquid alloys," Met. Trans. B, vol. B20, pp. 693-703, 1989.

[12]. L. V. Volkov, S. P. Shkuryakova, and N. Ba Khal, "Feasibility of producing cadmium-zinc alloy powders," Sov. Powder Metall. Met. Ceram., vol. 24, no. 8, pp. 589-592, Aug. 1985.

[13]. A. Vegh, C. Mekler, A. Dezso, and G. Kaptay, "[P114] Grain-boundary segregation transition in the binary Fe-P alloy," Calphad, vol. 51 , p. 409 , Dec. 2015

[14]. S. T. Tanaka, K. Hack, T. Iida and Hara, "Application of thermodynamic databases to the evaluation of surface tensions of molten alloys, salt mixtures and oxide mixtures," Zeitschrift Fuer Met., vol. 87, pp. 380-389, 1996.

[15]. T. Stuczyñski, "Metallurgical problems associated with the production of aluminium-tin alloys," Mater. Des., vol. 18, no. 4-6, pp. 369-372, Dec. 1997.

[16]. R. N. Singh and F. Sommer, "Thermodynamic investigation of viscosity and diffusion in binary liquid alloys," Phys. Chem. Liq., vol. 36, no. 1, pp. 17-28, Feb. 1998.

[17]. R. N. Singh and I. Ali, "Structure-induced order-disorder transformation in Cd-Na liquid alloys," Zeitschrift für Met., vol. 97, no. 4, pp. 382-387, Apr. 2006.

[18]. R. Novakovic, D. Giuranno, E. Ricci, S. Delsante, D. Li, and G. Borzone, "Bulk and surface properties of liquid Sb-Sn alloys," Surf. Sci., vol. 605, no. 1-2, pp. 248-255, Jan. 2011

[19]. A. Luo and M. O. Pekguleryuz, "Cast magnesium alloys for elevated temperature applications," J. Mater. Sci., vol. 29, no. 20, pp. 5259-5271, 1994.

[20]. E. O. Ilo-Okeke, B. C. Anusionwu, and O. Popoola, "Thermodynamic evaluation of viscosity in In-Zn and Sn-Zn liquid alloys," Phys. Chem. Liq., vol. 43, no. 4, pp. 333-342, Aug. 2005.

[21]. W. Gąsior, P. Fima, and Z. Moser, "Modeling of the thermodynamic properties of liquid Fe-Ni and Fe-Co alloys from the surface etnsion data," Arch. Metall. Mater., vol. 56, no. 1, Jan. 2011.

[22]. P. J. Flory, "Thermodynamics of High Polymer Solutions," J. Chem. Phys., vol. 10, no. 1, p. 51, 1942.

[23]. E.A.Guggenheim, Mixtures. Oxford University. Press, London, 1952.

[24]. D. Adhikari, "Inhomogeneity in structure of MgPb liquid alloy," Phys. B Condens. Matter, vol. 406, no. 3, pp. 445-448, 2011.

[25]. R. P. Koirala, B. P. Singh, and D. Adhikari, "Thermodynamic,surface and viscous properties of molten Ga-Zn Alloys," J. Adv. Phys., vol. 3, no. 2, pp. 163-170, Jun. 2014.

[26]. I. Koirala, I. S. Jha, B. P. Singh, and D. Adhikari, “Thermodynamic, transport and surface properties in In-Pb liquid alloys," Phys. B Condens. Matter, vol. 423, pp. 49-53, 2013.

[27]. D. Adhikari, "Alloying behaviour of molten Ni-Pt and Al-Ge alloys," Phase Transitions, vol. 85, no. 9, pp. 824-830, Sep. 2012.

[28]. D. Adhikari, B.P. Singh, and I.S. Jha, "Structural and energetic anomaly in liquid Na-Sn alloys," J. Mol. Liq., vol. 167, pp. 52$56,2012$.

[29]. D. Adhikari, I. S. Jha, and B. P. Singh, "Transport and surface properties of molten Al-Mn alloy," Adv. Mater. Lett., vol. 3, no. 3, pp. 226-230, Jul. 2012

[30]. B. P. Alblas, C. van der Marel, W. Geertsma, J. A. Meijer, A. B. van Oosten, J. Dijkstra, P. C. Stein, and W. van der Lugt, "Experimental results for liquid alkali-group IV alloys," J. Non. Cryst. Solids, vol. 61-62, pp. 201-206, Jan. 1984.

[31]. O. E. Awe, Y. A. Odusote, O. Akinlade, and L. A. Hussain, "Thermodynamic properties of some gallium-based binary alloys," Phys. B Condens. Matter, vol. 403, no. 17, pp. 2629-2633, Aug. 2008.

[32]. A. B. Bhatia and D. E. Thornton, "Structural aspects of the electrical resistivity of binary Alloys," Phys. Rev. B, vol. 2, no. 8, pp. 3004-3012, Oct. 1970.

[33]. I. S. Jha, D. Adhikari, J. Kumar, and B. P. Singh, “Anomaly in mixing properties of lithium-magnesium liquid alloy,” Phase Transitions, vol. 84, no. 11-12, pp. 1075-1083, 2011.

[34]. G. Kaptay, "A unified equation for the viscosity of pure liquid metals," Z. Met., vol. 96, pp. 1-8, 2005.

[35]. R. Novakovic, "Thermodynamics, surface properties and microscopic functions of liquid Al-Nb and Nb-Ti alloys," J. Non. Cryst. Solids, vol. 356, no. 31-32, pp. 1593-1598, Jul. 2010.

[36]. V. K. Ratti and A. B. Bhatia, "Number concerntration strucure factors and their long wave-length limit in multicomponent fluid mixture," Phys. Chem. Liq., vol. 6, pp. 201-213, 1977.

[37]. R. N. Singh and K. K. Singh, “Energetic effect in liquid Antimony-Indium alloys,” Mod. Phys. Lett. B, vol. 9, no. 26 n27, pp. 1729-1738, Nov. 1995.

[38]. S. K. Yadav, L. N. Jha, and D. Adhikari, “Thermodynamic and structural behaviour of Mg-Ga melt at $923 \mathrm{~K}$," J. Adv. Phys., vol. 3, no. 3, pp. 248-253, Sep. 2014.

[39]. S. K. Yadav, L. N. Jha, and D. Adhikari, "Thermodynamic and structural properties of Bi-based liquid alloys," Phys. B Condens. Matter, vol. 475, pp. 40-47, 2015.

[40]. W. H. Harrison, Pseudopotential in the theory of metals. New York: Benjamin, 1966.

[41]. I. Budai, M. Z. Benko, and G. Kaptay, "Comparison of different theoretical models to experimental data on viscosity of binary liquid alloys,” Mater. Sci. Forum, vol. 537, pp. 489-496, 2007.

[42]. E. A. Moelwyn-Hughes, Physical Chemistry. Oxford, London:Longmans Green and Co., 1974.

[43]. E. A. Brandes and G.B. Brook, Ed., Smithells Metals Reference Book, 7th editio. Butterworth-Heinemann Linacre House, Jordan Hill, Oxford, 1992.

[44]. J. A. V. Butler, "The Thermodynamics of the surfaces of solutions," Proc. R. Soc. A Math. Phys. Eng. Sci., vol. 135, no. 827, pp. 348-375, Mar. 1932

[45]. R. Hultgren, P. D. Desai, D. T. Hawkins, M. Gleiser, and K. K. Kelley, Selected Values of the Thermodynamic Properties of Binary Alloys. Metal Park, ASM International, OHIO, 1973. 